\title{
O USO DE TECNOLOGIAS COMO RECURSOS DIDÁTICOS NO ENSINO DE
} ASTRONOMIA.

\author{
MARQUES, Renan ${ }^{1}$ \\ CANCIAN, Queli Ghilardi ${ }^{2}$ \\ DA SILVA, João Vitor ${ }^{3}$ \\ MALACARNE, Vilmar ${ }^{4}$
}

\begin{abstract}
RESUMO: A presente pesquisa tem como objetivo a, abordar o uso da tecnologia em aulas de Ciências, especificamente para o trabalho com o conteúdo Astronomia, considerando que os conteúdos dessa área estão presente tanto nos anos iniciais quanto nos anos finais do Ensino Fundamental. Assim, pretende-se analisar, e descrever o potencial de aplicativos que possam ser utilizados nas aulas, como, por exemplo, o software de simulação denominado Stellarium. Trata-se de um planetário virtual gratuito, em que é possível realizar visualizações do céu, simulando tanto o céu diurno e noturno, assim como os planetas, luas, estrelas, entre outros corpos celestes, com informações detalhadas a respeito de cada um. Há três dimensões presentes no software, sendo que as imagens podem ser vistas simulando: a visão a olho nu, com binóculo ou com telescópio. Portanto, espera-se com este trabalho a divulgação deste recurso para a prática da docência, que pode ser de grande potencial para o trabalho com o conteúdo astronomia.
\end{abstract}

Palavras Chave: Ensino de Ciências; Astronomia, Tecnologias

\section{INTRODUÇÃO}

O ensino de Ciências tem sido tema de diversas pesquisas no meio educacional. Como exemplo, cita-se a preocupação com a formação de professores para o ensino da disciplina, por meio de pesquisas como as de Ducatti-Silva (2005), Gatti (2010) e Silva (2014). Essas pesquisas, de forma geral, afirmam que a formação para o ensino de Ciências nos anos iniciais do Ensino Fundamental acontece de forma precária. Isso ocorre, entre outros fatores, pela carga horária destinada à disciplina na formação docente ser pequena. Em decorrência dessa formação precária, o ensino dos conteúdos é prejudicado, pois de acordo com Bonando (1994), por exemplo, as aulas ficam restritas à lousa, em aulas tradicionais e memorísticas.

\footnotetext{
${ }^{1}$ Graduando em Biologia - Universidade Estadual do Oeste do Paraná - UNIOESTE, e-mail: renancezarmarques@ hotmail.com

${ }^{2}$ Mestranda pelo PPGE - Programa Pós-graduação em Educação da Universidade Estadual do Oeste do Paraná UNIOESTE, e-mail: quelicancain@gmail.com

3 Graduando em pedagogia -- Universidade Estadual do Oeste do Paraná - UNIOESTE, e-mail: joaovitorsilva1998@outlook.com.br

${ }^{4}$ Doutor em Educação - PPGE - Programa Pós-graduação em Educação (Mestrado) Universidade Estadual do Oeste do Paraná - UNIOESTE, e-mail: vilmar.malacarne@unioeste.br
} 
Nesse sentido, é possível pensar a respeito de aulas que utilizem recursos didáticos diversificados, para além da lousa e do livro didático. A tecnologia, por exemplo, é um recurso que pode auxiliar o professor no trabalho com alguns conteúdos. Ela promove maior interação, curiosidade, abrangendo todos os discentes, pois, principalmente no século que vivem a tecnologia esta fortemente ligada ao cotidiano destes.

Neste panorama, as Diretrizes Curriculares Nacionais da Educação (DCNs) abordam que “[...] as escolas devem propiciar ao aluno condições de desenvolver a capacidade de aprender, [...], mas com prazer e gosto, tornando suas atividades desafiadoras, atraentes e divertidas" (BRASIL, 2013, p.117). Por esse viés, se a escola deve promover tais condições, é de indubitável importância que a mesma utilize de recursos atrativos e que proporcione um aprofundamento maior em relação aos conteúdo.

Assim, nesse trabalho será discutido de que forma a tecnologia pode auxiliar no ensino do conteúdo de astronomia, em especial com o software stellarium. Pois, o mesmo pode tornar mais instigante o aprendizado do discente.

\section{A ASTRONOMIA NA EDUCAÇÃO BÁSICA: ALGUMAS CONSIDERAÇÕES}

Os fenômenos astronômicos tem sua importância na organização social considerando ser regulador de tempo natural e que diante das tarefas rotineiras do ser humano essa organização se torna indispensável (CANIATO, 1974). O ensino de Astronomia deve ser apresentado de modo a estabelecer um vínculo com a vida prática das pessoas e não ser visto apenas como um mero estudo sistematizado e científico.

Langhi apud Franknoi (1995) ressalta o valor desse ensino para a construção de várias habilidades do aluno em formação, seja na capacidade de calcular, comparar, classificar objetos e eventos, para a comunicação, experimentação, exploração, imaginação, mediação, observação, raciocínio lógico entre outros. Conhecer os conceitos e a historicidade que fundamenta a Astronomia e como esta influência decisivamente na vida social, cultural e econômica das pessoas se torna um passo importante para a aquisição desse conhecimento.

Neste ponto, é imprescindível destacar a importância vinculada ao ensino participativo, em que o aluno pode se aproximar do tema a partir de discussões e também, a partir da utilização de instrumentos interativos, como os aplicativos de celulares e experimentos científicos.

O livro didático é um instrumento de grande importância para o trabalho em sala de aula, entretanto, muitas vezes é o único recurso utilizado pelo professor (LONGHINI, 2008). Considerando isso, os materiais que saem da rotina tradicional, podem ser sinônimos de 
aprendizagem para o aluno.

No que se refere à Astronomia, os conhecimentos adquiridos nos últimos cinquenta anos, por conta das missões espaciais, por exemplo, ampliaram nossa visão sobre o Universo quanto à sua origem, evolução e formação (LONGHINI; MENEZES, 2010, p. 434).

Considerando que a ciência tem um papel de enorme relevância no meio científico e escolar. Quando trabalhada de forma adequada em sala de aula, ela pode despertar um senso crítico nos estudantes em relação às diversas concepções inadequadas ou apenas superficiais que acabam adquirindo durante a vida escolar.

A astronomia é um tema interessante, no qual permite o deslumbramento e o fascínio frente a beleza do universo. O Sol torna as manhãs mais brilhantes e a Lua ilumina o céu todas as noites. Isso é astronomia, isso é vida. Então, porque não começar a mostrar as coisas incríveis que estão ao redor de cada um destes alunos, de uma forma mais criativa e lúdica? Popularmente conhecido, o método tradicional já mostrou que é “[...] pouco eficaz, seja do ponto de vista dos estudantes e professores, quanto das expectativas da sociedade" (BORGES, 2002, p. 292).

Poder entender o universo é algo impressionante, imagine poder ensinar tudo isso aos alunos? Quem sabe futuros cientistas? Este pensamento é capaz de mudar o ensino de astronomia falho que se tem nos dias atuais, pois o desprendimento do livro didático é um hábito que causa grandes polêmicas. Atividades com foco na aula prática, “[...] hoje em dia, criou-se o conceito de que só pode ser praticada em grandes observatórios ou por grandes instituições de pesquisa." (SAMPAIO; RODRIGUES, 2015, p. 88).

Segundo pesquisas, as dificuldades encontradas no ensino de astronomia estão ligadas às questões teórico-metodológicas, na qual o professor se depara com o desafio do saber fazer e como fazer. Diante disso, o livro é visto como um recurso didático que orienta o trabalho pedagógico, mas que, no entanto, o ensino não deve estar condicionado apenas à sua utilização. Sobre isso, Langhi e Nardi (2005) escreve:

[...] acreditamos que a inserção da Astronomia deveria ocorrer na formação inicial/continuada de professores, talvez garantindo uma mudança de postura dos mesmos em relação ao ensino deste tema. Contudo, a presença da Astronomia na formação de professores não deveria simplesmente resumir-se em apenas conteúdos, mas é necessário que se inclua ainda sugestões e orientações didáticas organizadas e definidas em função das diferentes realidades e necessidades dos docentes (LANGHI E NARDI, 2005, P.80).

A astronomia deve ser vista como um campo de estudo propício para o despertar da curiosidade e o interesse do aluno pelo conhecimento científico e sistematizado, colocando em 
prática estratégias que permitam o desvendar do saber ainda desconhecido.

Ainda segundo os autores (LANGHI; NARDI, 2005), as dificuldades apresentadas pelos professores estão vinculadas ao fato dos conteúdos serem difíceis de contextualizar, isso ocorre devido a sua má compreensão, o que de certo modo compromete o ensino-aprendizado

Os autores ainda reiteram que, há uma enorme falência no que diz respeito ao acesso à pesquisas que enriqueçam o repertório do professor; pelo tempo ser reduzido dificultando um ensino diferenciado; por falta de ideias e sugestões que possam orientar o trabalho pedagógico e pela questão da própria insegurança do professor frente ao tema proposto. É claro, que tudo isso se deve à falência de cursos de formação para o ensino de astronomia e suas respectivas especificidades.

Um dos fatores que também desmotivam esse ensino, de acordo com Nogueira e Canalle (2009), é pelo fato de haver ocorrido uma "diluição" das noções astronômicas, nas quais vários conceitos foram distribuídos em diferentes áreas do conhecimento.

[...] as noções básicas sobre o Sistema Solar são dadas nas aulas de geografia, as leis de movimentos dos planetas estão no curso de física, o andamento da corrida espacial no século 20 está na disciplina de história, e as descobertas mais sofisticadas sobre a origem do universo, pasme, não estão em lugar algum. (NOGUIERA E CANALLE, 2009, p.20).

Percebe-se que o ensino de astronomia apresenta algumas dificuldades de modo a não mais ser visto como um todo, por consequência dessa fragmentação e os alunos cada vez desmotivados em relação a esse estudo.

Sendo assim cabe ao professor o difícil papel de resgatar esse ensino, como um todo, através do estudo interdisciplinar. Para isso, é necessário que tenha uma formação adequada garantindo assim que sua atuação como professor, venha superar as dificuldades antes elencadas. Compreender os conteúdos das áreas do conhecimento, serão de suma importância para o seu exercício didático (BRASIL, 2001). Um dos elementos apontados por Ganzotti (2013) é o rompimento das "dicotomias como reflexão/ação ou teoria/prática", que estabeleceria um vínculo mais próximo entre as pesquisas com foco na prática docente e as reais necessidades indicadas pelos professores.

É importante ainda considerar, que um dos recursos que podem estabelecer um elo de superação das dificuldades da prática docente e o despertar do interesse e curiosidade do aluno nesse universo da Astronomia, seria a utilização de ferramentas tecnológicas, que chamam a atenção e instigam a compreensão acerca da temática apresentada. 


\section{AS TECNOLOGIAS E SEU USO NO ENSINO DA ASTRONOMIA}

Desde o início da humanidade o ser humano vem buscando mecanismos e formas de estudar o universo e os astros sendo a astronomia uma das primeiras ciências a ser estudada pelo homem. De Hesíodo a Updike, o universo sempre esteve muito perto da civilização. Suas atribuições têm sido usadas tanto para agendar o cultivo da terra, no passado quanto como fonte de inspiração para os escritores em todas as épocas. O mistério das Estrelas mexeu profundamente como a imaginação dos povos e converteu-se em matéria-prima para o desenvolvimento da filosofia, das religiões, da poesia e da Ciência, que ajudou e nos ajuda até hoje a produzir conhecimentos e tecnologias que trouxeram conforto, qualidade de vida, cultura e desenvolvimento econômico e social.

Com o decorrer do tempo a divulgação científica e o incentivo à pesquisa teve uma grande queda entre a humanidade. Como ressalta Horvath (2013), as ciências naturais estão cada vez menos "naturais" isso gera problemas muitas vezes irreparáveis no aprendizado em sala.

Nessa perspectiva, o ensino precisa ser moldado com a sua realidade atual e cabe ao professor ser mediador deste feito, estimulando o aluno, criando interesse pelo conteúdo trazendo assim um significado e um motivo estimulante ao estudo da Astronomia fazendo assim com que o aluno compreenda o papel do homem no universo e que crie também seus conceitos ideológicos que possibilitarão uma aula experimental com hipóteses estimulando assim o senso crítico, sobretudo despertando talentos por promover a participação empreendedora e o protagonismo dos alunos.

Considerando esses fatores, uma forma que o professor pode encontrar para estimular o interesse e acompanhar esse rápido desenvolvimento da ciência em sala é o uso de tecnologias como aplicativos que vêm para contribuir com o ensino.

Existem inúmeros aplicativos didáticos que influenciam diretamente no ensino facilitando a compreensão dos alunos e despertando um grande interesse, em sua maioria das vezes são aplicativos gratuitos e de fácil acesso, alguns deste são;

A carta celeste, por exemplo, é um aplicativo (App) gratuito que está disponível tanto para sistemas Androids como para IOS. O App possibilita o aluno visualizar as constelações com seu celular. Para isso, basta abrir o App que aciona a câmera, e apontá-la para o céu. $\mathrm{O}$ aplicativo lhe dá o desenho e os nomes das constelações para qual a câmera esta apontada. 
Esse aplicativo pode ser utilizado no ensino de astronomia tanto nos anos iniciais como nos finais, trazendo uma perspectiva que de início era de difícil compreensão aos alunos, mas com suas funções facilita a compressão da formação das constelações que delimitam as regiões do Céu noturno. Com esse recurso, vários conceitos podem ser trabalhados tais como o contexto histórico relacionado com a criação das constelações, as origens dos nomes e as funções da demarcação do céu para a humanidade.

Muito parecido com a funcionalidade do Carta celeste, temos o aplicativo Star Walk. Este App utiliza bússola, GPS, o acelerômetro e o giroscópio do dispositivo para dar a localização dos planetas e estrelas visíveis em tempo real, mostrando onde cada um está no céu. O app já tem mapeado mais de 120 mil estrelas, além das 88 constelações. O mais interessante deste aplicativo é que o aluno consegue mudar sua localização e apreciar o céu noturno de outros pontos da Terra.

Didaticamente falando um dos programas mais acessíveis e completos para o estudo de astronomia é o Stellarium, que apesar de ser um app pago tem um baixo custo e uma fácil acessibilidade, para usuários iniciantes que nunca tiveram contato com nada do gênero por exemplo.

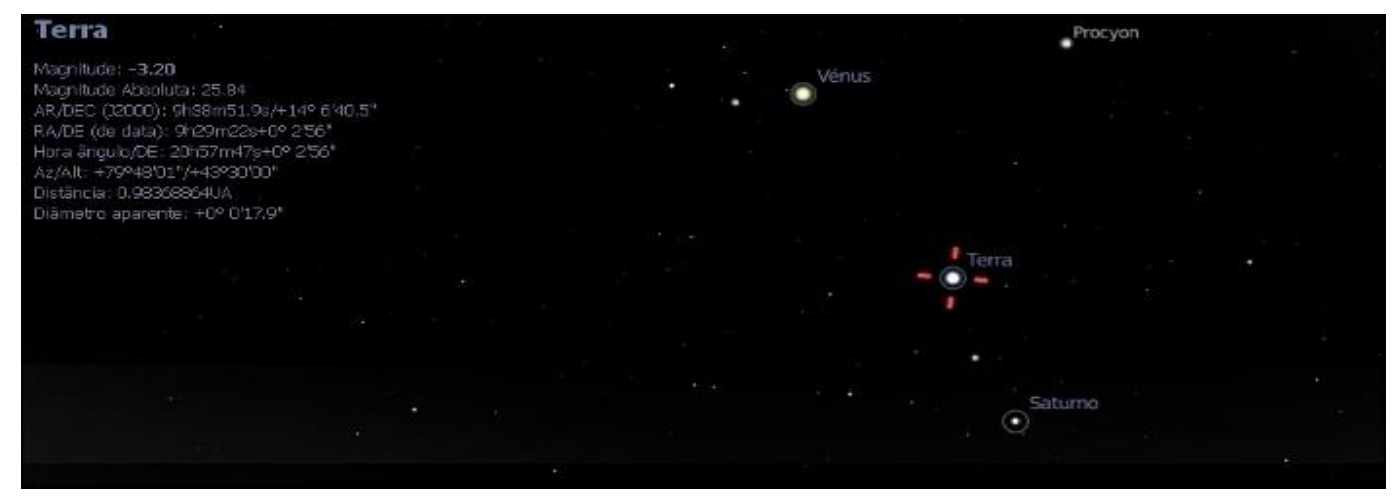

Figura 1 Céu do Stellarium - Print Feito pelo autor extraído do próprio programa

Ele possui uma interface bem chamativa que provoca o usuário/ aluno a explorá-lo e descobrir suas funções dentre todos os recursos do Stellarium. Talvez o que mais impressione seja a possibilidade de visualizar o céu dos diferentes planetas, satélites naturais e estrela do sistema solar. Se você colocar a opção para ver o céu a partir do Sol, por exemplo, irá notar que a Terra é mostrada como os outros planetas: apenas um ponto (azul) no céu com a identificação "Terra". 


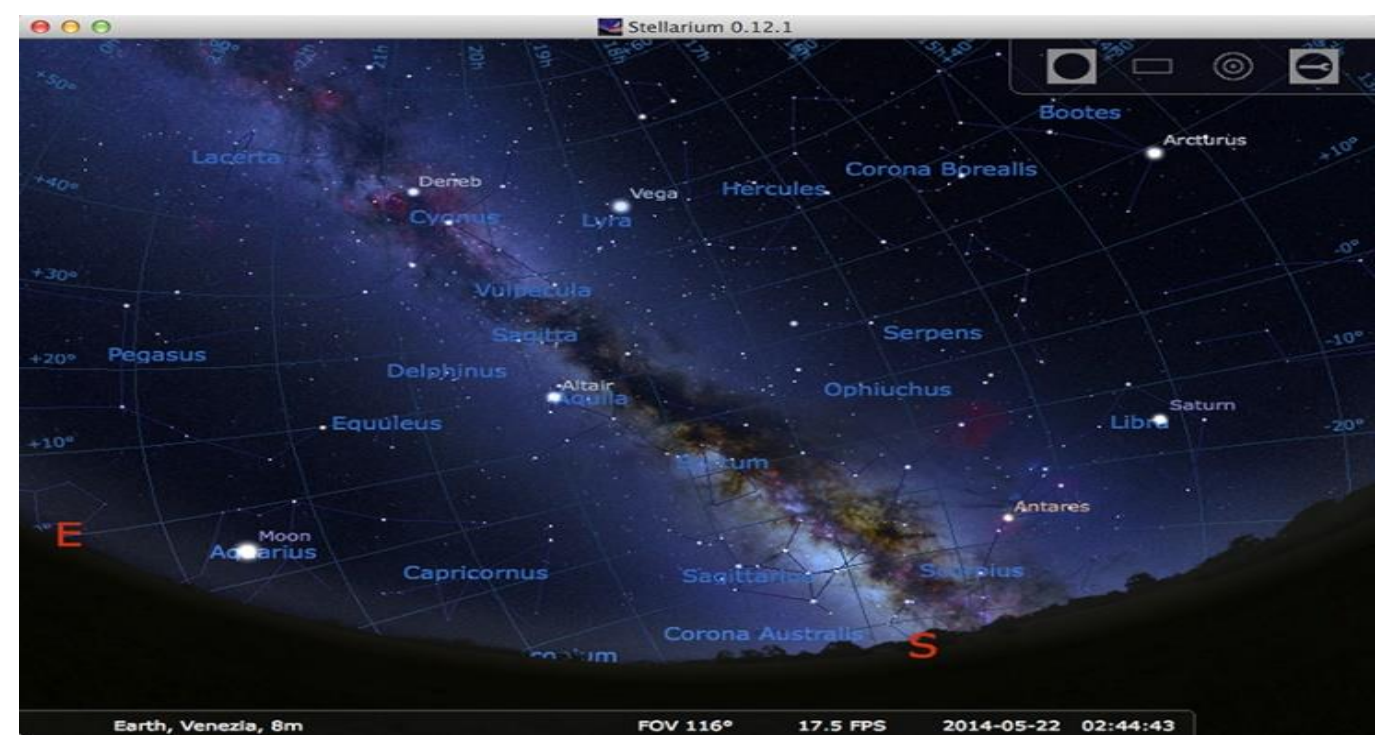

Figura 2 Céu do Stellarium - Print Feito pelo autor extraído do próprio programa

Outro recurso muito atraente no programa são as paisagens para simular o ambiente de observação. Você pode simular a visualização na Lua, Marte, em alto mar ou mesmo em uma montanha com muito gelo. A riqueza de detalhes impressiona até mesmo os mais acostumados com o programa.

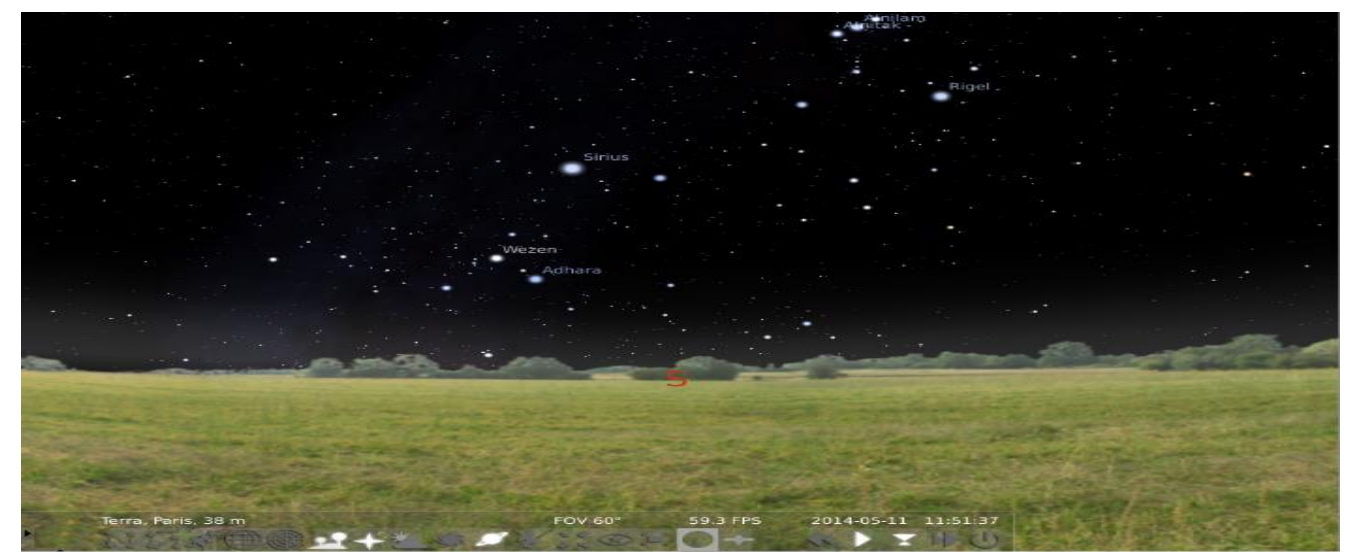

Figura 3 Céu do Stellarium - Print Feito pelo autor extraído do próprio programa

Em relação as constelações, por exemplo, o Stellarium nos traz os nomes e as figuras, a diferença em relação aos outros App citados acima, é que com é possível visualizar as constelações com os nomes originários de cada povo, como Egípcios, chineses e muitos outros. Ele também nos traz o nome dos planetas e suas luas com sua posição em tempo real como as luas de júpiter por exemplo. 


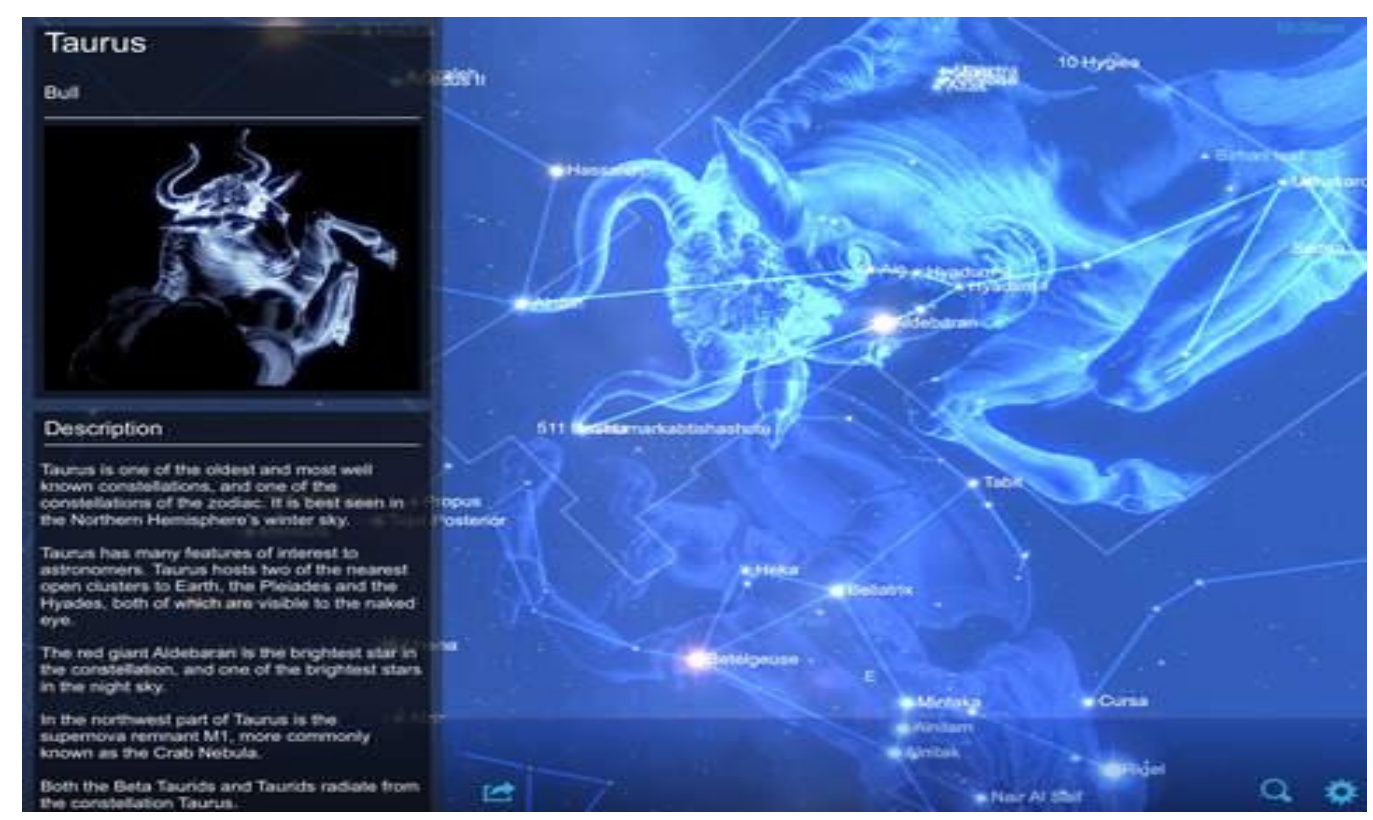

Figura 4 Constelação de Touro- Print Feito pelo autor extraído do próprio programa

Esse efetivamente é um dos aplicativos que apresenta uma das melhores possibilidades didáticas atendendo as necessidades de todos os anos que trabalham com Astronomia sendo um ótimo recurso ao docente.

É evidente que o uso das tecnologias no ensino são de extrema importância para que o aprendizado evolua a ponto de manter o interesse dos alunos pela Ciência e cabe ao professor utilizar o programa ou aplicativo que mais se adequa em sua matéria e a seu público.

\section{ENSINO DE ASTRONOMIA}

A Astronomia vai além de ser uma simples Ciência, "É um reflexo da nossa cultura; uma percepção dentro do desenvolvimento das ideias e ideias da humanidade" (COUPER e HENBEST, 2009, p.8), na qual se busca desvendar os segredos que existem no universo. De acordo com Nogueira (2009), na Grécia antiga a Astronomia se fez presente com grande influência na vida das civilizações, através da mitologia grega, com seus deuses que vinham explicar o que ainda estava fora do alcance do conhecimento da época. O autor reitera que há 13 mil anos com o surgimento da agricultura, a observação do céu ganha um valor prático incalculável, unindo a sofisticada noção humana de causa e efeito à transição para o período conhecido como revolução neolítica. Assim, ainda de acordo com Nogueira (2009), a Astronomia começa a fazer parte diretamente da sociedade com a influência das fases lunares e das estrelas. 
Simaan e Fontaine (2002, p.9) utilizam poemas de Hesíodo que dão indícios do início das observações referentes ao céu e de sua relação com o desenvolvimento da agricultura.

Ao despertar das plêiades, filhas de Atlas, dai início à colheita, e ao seu recolher, à semeadura.

Ordenai a vossos escravos que pisem, em círculos, o trigo sagrado de Deméter, tão logo surja a forca de Orion, em local arejado e eira redonda.

Quando Órion e Siriús alcançarem o meio do céu, e que a Aurora dos dedos de rosa conseguir enxergar Arcturo, então, Perseu, colhe e leva para casa todos os cachos das uvas.

Nessa estreita relação do homem com o cosmo, Nogueira (2009, p.17) afirma que “[...], a astronomia - foi a atividade que abriu as portas do mundo da Ciência para os seres humanos". Na mesma perspectiva, de acordo com os Parâmetros Curriculares Nacionais - PCN's, "No século XX, o espaço cósmico mostra-se palco concreto da aventura humana, quando se explora todo o Sistema Solar por meio de sondas e naves espaciais e o ser humano pisa na Lua (BRASIL, 1998, p.38)”. A partir desse momento, a Astronomia passa a ganhar força devido ao avanço tecnológico (DARROZ; HEINECK; PÉREZ, 2011) e seu estudo caracterizar-se pela observação dos fenômenos e dos elementos que constituem o universo. Conforme Ganzotti (2008, p.24) "Conhecer e analisar constantemente os astros do céu foi fundamental para compreender e localizar a própria Terra no Universo".

É importante observarmos que fenômenos astronômicos “[...] aguçam a curiosidade das pessoas, despertando nelas importantes questionamentos (PELLENZ, 2015, p.15)". Assuntos como viagens interplanetárias e a existência de vida em outros planetas se destacam nessas discussões, e torna esse estudo ainda mais instigante. É comum alunos do Ensino Fundamental levarem para a sala de aula estas e outras curiosidades. Assim, partindo desse entusiasmo, é possível a reflexão e o aprofundamento desse conhecimento, podendo ser um ponto de partida para esta e também para outras Ciências. Darroz; Heineck e Pérez (2011) abordam o interesse e o fascínio da Física, Química, Matemática, Geografia e Biologia pela Astronomia. Esse interesse aflorou-se devido ao avanço tecnológico e que "[...] proporcionou um vasto rol de conhecimentos na área" (DARROZ; HEINECK; PÉREZ, 2011, p.58). Pellenz (2015, p.16) também identifica as relações entre essa Ciência com as demais áreas do conhecimento e elenca o caráter epistemológico de cada uma delas. De acordo com a autora, compete à biologia e a química, pesquisas "acerca da vida" seja ela em nosso planeta ou em outros e questões que envolvam a "evolução do planeta" cabe a geologia e a planetologia. Ela 
reitera, que, ao "movimento dos corpos celestes e as leis que regem o universo" estão vinculados a física e a matemática e se encontram nos estudos realizados pela "astrofísica e a cosmologia".

Dessa forma, constatada a relevância dos estudos astronômicos, verifica-se também a importância do compartilhar esse conhecimento através do processo de ensino-aprendizado. Langhi e Nardi (2003) apontam as principais justificativas para ensinar astronomia. Uma dessas justificativas se respalda na ideia de que muitos alunos “[...] possuem conceitos espontâneos sobre o Universo" (p.4). Além disso, Fraknoi (1995 apud LANGHI e NARDI, 2003) ressalta o valor desse ensino para a construção das habilidades do aluno em formação. Seja na capacidade de calcular, comparar, classificar objetos e eventos, seja para a comunicação, experimentação, exploração, imaginação, observação, raciocínio lógico entre outros. Além disso, Ausubel (2003) afirma que a aprendizagem significativa só é qualificada quando há uma interação dos novos conhecimentos adquiridos com os conhecimentos que o indivíduo já possui, fazendo com que ocorram novas significações.

Neste contexto, é imprescindível que haja uma preocupação quanto ao ensino da Astronomia e de suas respectivas especificidades, pois “[...] compreender o Universo, projetando-se para além do horizonte terrestre, [...], pode nos dar novo significado aos limites do nosso planeta, de nossa existência no Cosmos, [...] (BRASIL, 1998, p. 41)”. Dessa forma, considerar aspectos didáticos e pedagógicos no ensino de Astronomia contribuirá de forma significativa para a retenção desse conhecimento.

Nogueira (2009) ressalta o valor da utilização de recursos práticos pedagógicos para o ensino de Astronomia, com o objetivo de mostrar na prática o que foi explicado em teoria. $\mathrm{O}$ autor traz outros exemplos de desafios e atividades práticas que podem ser utilizados em sala para reforçar a explicação teórica do docente. Exemplos como: relógio do sol, maquetes do sistema solar, etc. podem favorecer o processo de ensino-aprendizado. Outra alternativa apontada por Nogueira (2009) é a utilização de bolinhas de isopor para explicar fenômenos básicos como dia e noite, as estações do ano, eclipses e as fases da lua. Todos esses fenômenos são descritos (ou deveriam ser) nos livros didáticos de Ciências do Ensino Fundamental, e as atividades práticas reforçam essas explicações fazendo com que o aluno tenha uma melhor compreensão do conteúdo. Neste panorama podemos observar o quanto o ensino de astronomia é importante e como explorar novos horizontes pode repercutir de forma positiva para a aprendizagem contribuindo para que o professor atinja seu principal objetivo que é ensinar. 


\section{METODOLOGIA}

O presente trabalho foi realizado a partir de pesquisa bibliográfica, na literatura que segundo Severino (2007, p. 122) é "[...] aquela que se realiza a partir do registro disponível, decorrente de pesquisas anteriores, em documentos impressos como livros, artigos, teses, etc.". Dessa forma, para a realização das observações descritas no texto acima, foi realizado uma análise de apps voltado ao estudo da astronomia, e associando o uso destes, para o ensino deste conteúdo. Sendo assim efetivou-se uma análise qualitativa, onde segundo Michel (2009, p.37) prediz que nela “ [...] o pesquisador participa, compreende e interpreta", nesse sentido o artigo visou analisar como os conteúdos de Astronomia estão sendo trabalhados com as tecnologias disponíveis para o um melhor desenvolvimento e aprendizado dos alunos.

\section{CONCLUSÃO}

A astronomia é um dos conteúdos no ensino da disciplina de Ciências e Biologia, estando presente tanto nos anos iniciais como nos anos finais do Ensino Fundamental. Uma forma de esse conteúdo ser trabalhado de maneira diferenciada é utilizando recursos tecnológicos tais como softwares livres e aplicativos.

Considerando que o livro didático é um dos recursos didáticos mais utilizados, e que algumas pesquisas apontam que o professor fica dependente ao seu uso, utilizar esses recursos alternativos pode ser uma forma de variar as aulas e torná-las mais atrativas. Considerando isso, neste trabalho houve a pretensão de discutir a importância da tecnologia para o ensino da astronomia, em especial de recursos tecnológicos trazendo como exemplo o app stellarium. que é uma plataforma de fácil manuseio para o aluno como também um programa gratuito, o que facilita o acesso de uma maior número de alunos, e por consequência pode auxiliar de forma mais efetiva no aprendizado da astronomia, mostrando que o uso de tecnologias não só está presente em nossa realidade como é de certa forma, essencial no ensino para uma melhor compreensão do conteúdo, agindo como uma "Injeção de Motivação científica" nos alunos.

\section{REFERÊNCIAS BIBLIOGRAFICAS}

BRASIL. Ministério da Educação. Conselho Nacional de Educação. Diretrizes Curriculares 
Nacionais para a Formação de Porfessores da Educação Básica, em Nível Superior, Curso de Licenciatura, de graduação plena. Parecer CNE/CP n ${ }^{\circ}$ 9/2001, publicado no DOU de 18/01/2002. 44p. Brasília: MEC, 2001. Disponível em: http://portal.mec.gov.br/cne/arquivos/pdf/009.pdf. Acesso em: 28 de Novembro de 2017.

BRASIL. Diretrizes Curriculares Nacionais da Educação Básica. Brasília: MEC, 2013.

BONANDO, Paulo Antônio. Ensino de Ciências nas séries iniciais do $1^{\circ}$ grau - descrição e análise de um programa de ensino e assessoria ao professor. UFSCar, 1994. 147p. (Dissertação de Mestrado).

BORGES, A. Tarciso. Novos rumos para o laboratório escolar de Ciências. Belo Horizonte: Colégio Técnico da UFMG. v. 19, p. 291-313, 2002.

BRETONES, P. S. Dissertação (Mestrado) - Instituto de Geociências, Universidade de Campinas, Campinas. Disciplinas introdutórias de Astronomia nos cursos superiores do Brasil. 1999.

DUTRA, J. C. R.; CHRISTOFOLETTI, J. F.. Concepções de Ciências na Escola: reflexões. In: MALACARNE, Vilmar; STRIEDER, Dulce Maria (Org.). O Ensino de Ciências e Matemática: concepções e práticas. São Leopoldo: Trajetos Editorial, 2017. p. 137-153.

GANZOTTI, A. S. D. M; BORRAGINI, E. F.; KERBER, J. C.; HAETINGER, W.. Ensino de Astronomia: Cenários da Prática Docente no Ensino Fundamental. In: Revista LatinoAmericana de Educação em Astronomia - RELEA, N.16, p.27-43, 2013. Disponível em: web02.ufscar.br/relea/index.php/relea/article/download/181/247. Acesso em: 01 de Dezembro de 2017.

LANGHI, R.; NARDI, R. Dificuldades Interpretadas Nos Discursos de Professores dos Anos Iniciais do Ensino Fundamental em Relação ao Ensino da Astronomia. In: Revista LatinoAmericana de Educação em Astronomia - RELEA, n.2, p. 75-92, 2005. Disponível em: cienciaparaeducacao.org/.../langhi-rodolfo-nardi-r-dificuldades-interpretadas-nos-disc....

Acesso em: 27 de Novembro de 2017.

LONGHINI, M. D.; MENEZES, L. D. de D. Objeto virtual de aprendizagem no ensino de astronomia: algumas situações problema propostas a partir do software stellarium. Cad. Bras. Ens. Fís.: Uberlândia (MG), v. 27, n. 3. 2010. p. 433-448.

MALUF, V. J. Dissertação (Mestrado em Educação) - Instituto de Educação, Universidade Federal de Mato Grosso. A Terra no espaço: a desconstrução do objeto real na construção do objeto cientifico. 2000.

NOGUEIRA, S; CANALlE, J. B. G. Astronomia. In: NOGUEIRA, S.; CANALLE, J. B. G. Astronomia: Ensinos Fundamental e Médio. v.11. MEC, SEB; MCT; AEB. Brasília: 2009.

SAMPAIO, Thiago Alves de Sá Muniz; RODRIGUES, Eriverton da Silva. Método didático para o ensino de astronomia: utilização do software Stellarium em conjunto com aulas expositivas no ensino médio. C\&D-Revista Eletrônica da Fainor, Vitória da Conquista, v.8, n. 2. 2015. p. 87-97.

[Nas08] NASA. World Wind website. http://worldwind.arc.nasa.gov/ java/, 2008. 